\title{
Lower Extremity Position Test: A Simple Quantitative Proprioception Assessment
}

\author{
Hadas Ofek*1, Mordechai Alperin ${ }^{2}$ and Yocheved Laufer ${ }^{1}$ \\ ${ }^{1}$ Department of physical therapy, faculty of welfare and health studies, university of Haifa, Israel \\ ${ }^{2}$ Clalit health services, Haifa and western Galilee region, Israel
}

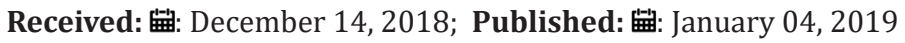

*Corresponding author: Hadas Ofek, Department of Physical Therapy, Faculty of Welfare and Health Studies, University of Haifa Israel

\begin{abstract}
Objective: To develop a quantitative, easy to use and inexpensive tool, for assessing proprioception of the lower extremity of older population, to evaluate its test-retest reliability in young and older adult population and examine its known-groups validity.

Design: Tool development and prospective test-retest assessment, one week apart, with a single assessor.

Participants: Older adults $(\mathrm{n}=60)$ and young subjects $(\mathrm{n}=20)$.

Main Outcome Measures: The Lower extremity position test (LEPT): seated subjects were asked to reproduce $12 \mathrm{~cm}$ or $22 \mathrm{~cm}$ distances, by verbally stopping passive movement of the foot produced by the tester on a plastic surface with distance markings. The deviation from the target point was measured as the mismatch score. T-test, ICC and Bland-Altman tests were used to determine group/leg differences and test-retest reliability.
\end{abstract}

Results: There was no difference in performance between the right and left extremity performance for older subjects. Good to fair test-retest reliability was demonstrated in the older subjects' group. The 95\% repeatability ranges were group related.

Conclusion: The Lower Extremity Position Test (LEPT) is a newly-developed testing tool with good clinical utility, reliable in older adults, and has known-group validity.

\section{Introduction}

Proprioception is the sense that enables to perceive the body's movement and position, and permits smooth and coordinated motor performance. It includes sense of position and of movement, along with sense of weight and movement velocity and direction $[1,2]$. Balance and gait performance are correlated with lower extremity position sense acuity, and proprioceptive decline is correlated with mobility decline and with risk of falls [3,4]. Falls are the most frequent mechanism of injury in elderly population, with high economical cost [5]. Proprioception is deteriorating in average in older adults, as seen for other senses, but not necessarily in all $[6,7]$. Therefore, assessment of proprioception performance is of interest in order to plan appropriate prevention and treatment. Proprioception assessment has been widely addressed in the last years, and is agreed to be of importance for diagnosis, for impairment degree assessment, for change over time and for the evaluation of treatment effect $[1,2,8,9]$.

However, to date quantitative methods are expensive and clinically unavailable, and therefore not in routine use [1]. Clinically, lower extremity proprioception is measured predominantly by assessing detection of movement and/or discrimination of movement direction, following passive movement of the joint; presenting categorical ratings (intact, impaired, absent; 0-1-2) $[2,10]$.Thus, there is a need for a quantitative proprioception assessment tool that will meet requirements of psychometric properties and of clinical utility (in terms of cost, time to administer, limited need for special equipment and training, and portability) $[1,10]$. The brief kinesthesia test is such a quantitative tool for assessing upper extremity proprioception. It is brief, easy 
to administer, inexpensive, and able to evaluate performance in population of different ages, while offering a ratio scale [11].

\section{Aim}

The aim of this study was to develop a quantitative (ratio scale) proprioception assessment tool for the lower extremity as a functional structure (contrary to assessing a single joint), and to test its test-retest reliability and its known-groups validity between young and older adults. It was based on the concept of the brief kinesthesia test for the upper extremity [11] but uses passive movement in order to prevent motor direction information to intervene.

\section{Methods}

\section{Participants}

A convenience sample of 60 older adults (over 60 years-of-age) with no neurological disorders, and a control group of 20 healthy adults (18-30 years-of-age) was recruited. Older adult volunteers were tested at municipal centers for the elderly and in independentliving senior housing. Young volunteers were recruited from the university student body. Inclusion criteria were age related, walking ambulation in everyday living situations, and the cognitive ability to follow the test's procedure. Exclusion criteria were a diagnosed neurological pathology (e.g. Parkinson's disease, stroke, peripheral neuropathy) and reduced foot sensation determined by failure to identify touch of a 5.07 (10 gram) monofilament (in order to exclude undiagnosed peripheral neuropathies or other undiagnosed conditions of sensory loss) [12]. The study was approved by the Institutional Review Board of the Faculty of Social Welfare and Health Sciences at the university. All subjects provided written informed consent prior to enrollment.

\section{Instrument and Testing Procedure}

Instrument: A tool aimed to assess the proprioception ability of the lower extremity (forward reach with the foot in sitting position, combining movement of knee and ankle) was developed. The test kit was comprised of a thin sheet of plastic surface (A3 sized paper nyloned) taped to the floor. A ruler was placed along its middle to measure distance moved. Two lines were drawn at the 12 and $22 \mathrm{~cm}$, perpendicular to the ruler distance (Figure 1). The 12 and $22 \mathrm{~cm}$ distances were chosen in order to standardize, on the basis of the upper extremity kinesthesia test, were medium and long distances only were found to be of use [11], and after trials with individuals of different height and leg length.

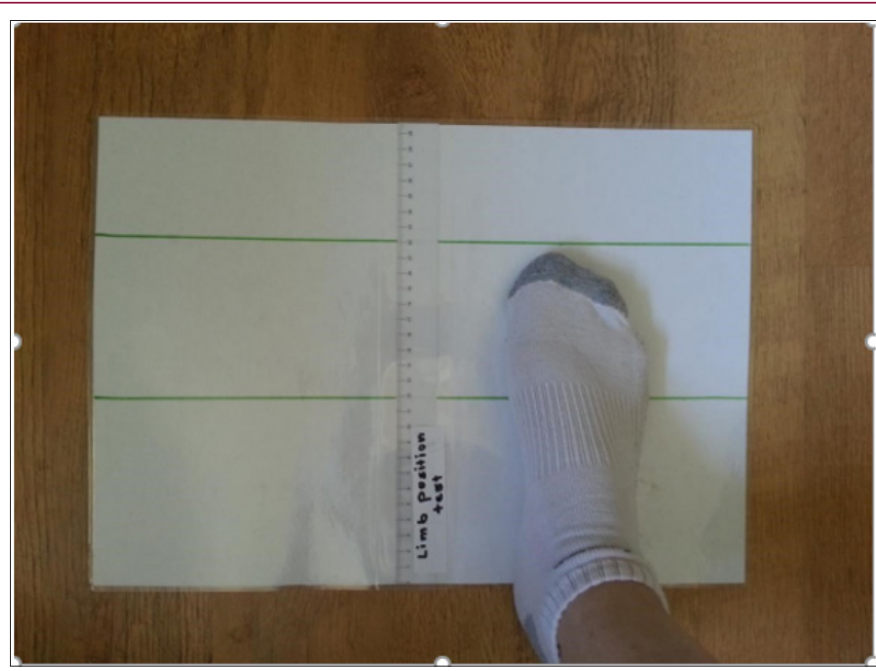

Figure 1: The Lower Extremity Position Test tool.

\section{Testing Procedure}

The subject was blindfolded and seated in a standard chair, with socks on (to eliminate friction and touch input as much as possible). A visual demonstration and a verbal explanation using the upper extremity were provided to ensure the instructions were understood. The test was performed with a slow passive movement of the foot on the plastic surface, repeated twice. The movement was administered by the tester, starting at the edge of the plastic surface $(0 \mathrm{~cm}$ on the ruler), with no active movement by the subject, to eliminate motor knowledge interference. For each repetition, the tester first moved the foot, so the toes reached either the $12 \mathrm{~cm}$ or the $22 \mathrm{~cm}$ line, brought it back to the starting point; then, moved it again to the point where the subject said "stop". The difference between the designated distance and the point where the subject asked to stop the movement was measured in half centimeters
$(0.5 \mathrm{~cm})$. The test was held twice for each distance for both feet, in a random order between distances and feet, and an average of mismatch was calculated for each distance.

\section{Study Procedure}

Prospective data gathering was planned, following the tool development procedure. All subjects were tested by the same tester on two occasions, one week apart. Demographic data, including age and gender were collected from all participants. Walking independence and the use of assistive device were gathered for older volunteers.

\section{Statistical Analysis}

Descriptive statistics of subjects' characteristics and the test results included mean, standard deviation (SD) and range. T-test $(2,2)$ was performed to determine differences in scores between 
groups, in order to verify known-groups validity [13]. T-test $(2,1)$ was performed to determine differences in scores between right and left leg performance within group. Test retest reliability was analyzed with the intraclass correlation analysis (ICC2,1). The interpretation of the ICC was: $0-0.25$ little to no correlation; 0.26-0.50 fair degree of correlation; $0.51-0.75$ moderate to good correlation; and 0.76-1 good to excellent correlation [13]. BlandAltman analysis was used to determine absolute reliability, as determined by the $95 \%$ repeatability measure, which is the $95 \%$ precision interval for repeated tests under similar condition [14].

\section{Results}

A total of 80 subjects ( 60 older adults and a control group of 20 young adults) met the inclusion criteria and volunteered to participate in the study. Subject characteristics are provided in Table 1. The mean and standard deviation for the position test score (per group, distance in $\mathrm{cm}$, extremity and testing session) are presented in Table 2 . T-test $(2,1)$ found no significant differences for the older subjects' group between right and left legs' performance. For the young subjects' group no significant difference was found for the $12 \mathrm{~cm}$ distance, but the $22 \mathrm{~cm}$ distance showed significant difference $(p=0.04)$, as the left leg performed better with a smaller mismatch $(0.76 \pm 0.46)$ then the left leg $(1.04 \pm 0.37)$ at time1. T-test $(2,2)$ found significant differences for right $12 \mathrm{~cm}(\mathrm{p}=0.04)$, for left $12 \mathrm{~cm} \mathrm{(} \mathrm{p}=0.02)$, and for left $22 \mathrm{~cm} \mathrm{(} \mathrm{p}=0.01)$. The difference for right $22 \mathrm{~cm}$ was not found significant Figure 2 demonstrates the mean deviation distance, thus the movement reproduction error, for right/ left leg for the 12 and $22 \mathrm{~cm}$ distances tested at time 1.

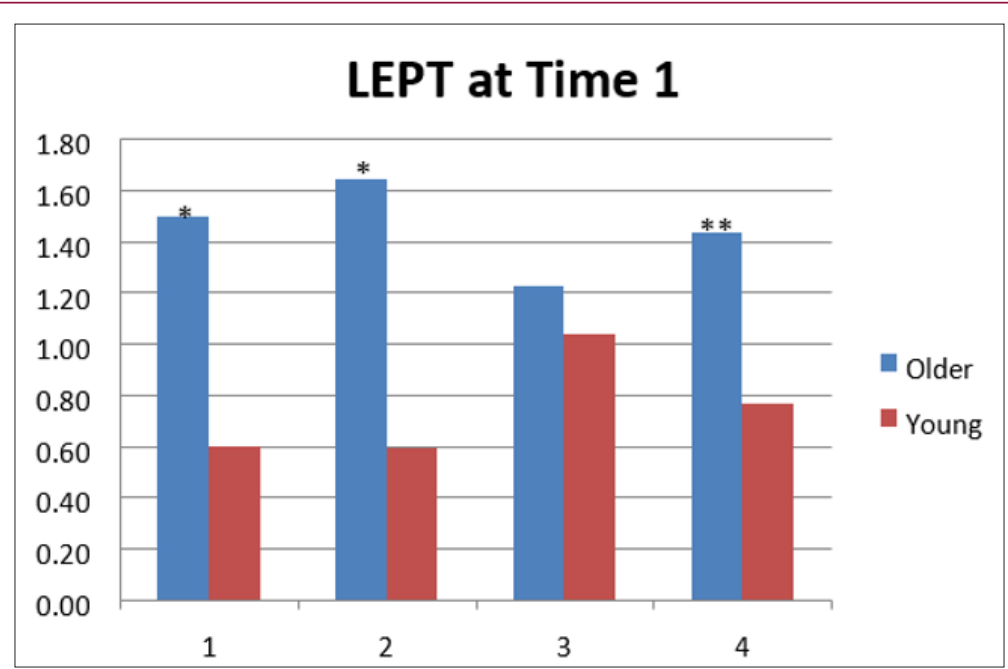

Figure 2: Deviations (cm) of lower extremity from the 12/ $22 \mathrm{~cm}$ target per group, leg at time 1.

Table 1: Characteristics of study participants, by group.

\begin{tabular}{|c|c|c|}
\hline Characteristic & Older $n=60$ & Young $\mathrm{n}=\mathbf{2 0}$ \\
\hline Age (years; mean \pm SD) & $76 \pm 10$ & $24 \pm 3$ \\
\hline Gender (male/female) & $8 / 52$ & $6 / 14$ \\
\hline Motor dominance (right/left) & $54 / 6$ & $19 / 1$ \\
\hline $\begin{array}{c}\text { Walking ability (indoor independent/ with walking aid/ } \\
\text { personal assistance) }\end{array}$ & $38 / 20 / 2$ & 20 \\
\hline
\end{tabular}

Table 2: Deviations (cm) of lower extremity from the 12/ $22 \mathrm{~cm}$ target per group, leg and testing session (mean \pm standard deviation (range).

\begin{tabular}{|c|c|c|c|c|}
\hline \multirow{2}{*}{ Group } & \multicolumn{2}{|c|}{ First session } & \multicolumn{2}{c|}{ Second session } \\
\hline \multirow{2}{*}{ Young $12 \mathrm{~cm}$} & Right & Left & Right & $0.55 \pm 0.24$ \\
\cline { 2 - 5 } & $0.60 \pm 0.31$ & $0.59 \pm 0.39$ & $0.65 \pm 0.29$ & $(0.25-1)$ \\
\hline \multirow{2}{*}{ Young $22 \mathrm{~cm}$} & $(0-1)$ & $(0-1.5)$ & $0-1)$ & $0.78 \pm 0.49$ \\
\cline { 2 - 5 } & $1.04 \pm 0.37$ & $0.76 \pm 0.46$ & $(0.25-1.5)$ & $(0-1.75)$ \\
\hline \multirow{2}{*}{ Older $12 \mathrm{~cm}$} & $(0-1.5)$ & $(0.25-2)$ & $1.20 \pm 1.14$ & $(1.17 \pm 1.20$ \\
\cline { 2 - 5 } & $1.33 \pm 1.34$ & $1.47 \pm 1.26$ & $(0-5.25)$ & $(0-5.5)$ \\
\hline \multirow{2}{*}{ Older 22 cm } & $(0-8)$ & $(0-6)$ & $1.09 \pm 1.06$ & $1.25 \pm 1.39$ \\
\cline { 2 - 5 } & $1.22 \pm 1.01$ & $(0-4) \pm 1.14$ & $(0-6)$ & $(0-8)$ \\
\hline
\end{tabular}

Cite this article: Ofek H, Alperin M, Laufer Y. Lower Extremity Position Test: A Simple Quantitative Proprioception Assessment. Biomed J Sci \& Tech Res 12(5)-2019. BJSTR. MS.ID.002306. DOI: 10.26717/ BJSTR.2019.12.002306. 
The results of the test-retest analysis are presented in Table 3. Good test-retest reliability was also demonstrated for the right leg of the older subjects' group for the $12 \mathrm{~cm}$ and $22 \mathrm{~cm}$ distances (ICC $=0.60$ and 0.62 , respectively). Fair reliability was demonstrated for older subjects' left leg for the $12 \mathrm{~cm}$ and $22 \mathrm{~cm}$ distances (ICC $=0.33$ and 0.38 respectively). Poor reliability was found for both distances and legs of the young subjects. The results of the testretest analysis are presented in Table 3. Good test-retest reliability was also demonstrated for the right leg of the older subjects' group for the $12 \mathrm{~cm}$ and $22 \mathrm{~cm}$ distances (ICC $=0.60$ and 0.62 , respectively). Fair reliability was demonstrated for older subjects' left leg for the $12 \mathrm{~cm}$ and $22 \mathrm{~cm}$ distances (ICC=0.33 and 0.38 respectively).
Poor reliability was found for both distances and legs of the young subjects. Results for Bland-Altman plots are presented in Figures 3 \& 4 For the $12 \mathrm{~cm}$ distance, the intra-tester 95\% repeatability results ranged from -3.01 to 3.59 and from 3.50 and 4.45 in older subjects for the right and left feet, respectively; and from -0.90 to 0.80 and -0.98 to 1.05 for the young subjects for the right and left feet, respectively. The intra-tester $95 \%$ repeatability results ranged, for the $22 \mathrm{~cm}$ distance, from -2.05 to 2.31 and 2.97 to 3.32 among older subjects for the right and left feet, respectively; and from -0.80 to 1.28 and from -1.11 to 1.08 for the young subjects for the right and left feet, respectively. No or minimal bias was demonstrated.
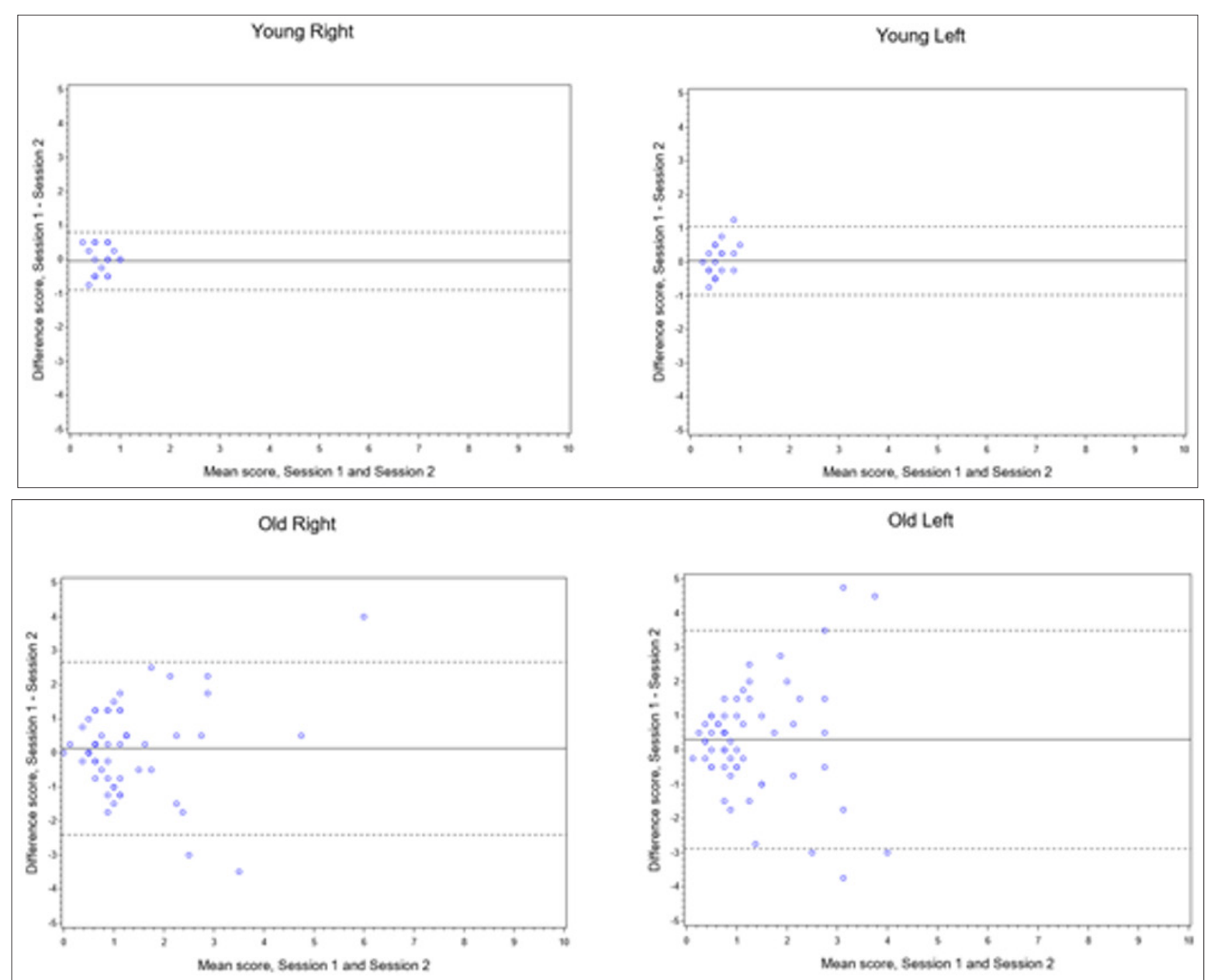

Figure 3: Bland-Altman plots for agreement between two testing sessions, position test, $12 \mathrm{~cm}$ distance (solid line, mean difference between testing sessions; dashed line, limits of agreement).

Table 3: Test-retest reliability (ICC) results for group and leg.

\begin{tabular}{|c|c|c|c|c|}
\hline \multirow{2}{*}{ Group } & \multicolumn{2}{|c|}{$\mathbf{1 2} \mathbf{~ c m}$ distance } & \multicolumn{2}{c|}{22 cm distance } \\
\cline { 2 - 5 } & Right & Left & -0.19 & Left \\
\hline Young & -0.02 & -0.53 & 0.52 & 0.38 \\
\hline Older & 0.6 & 0.33 & 0.62 \\
\hline
\end{tabular}



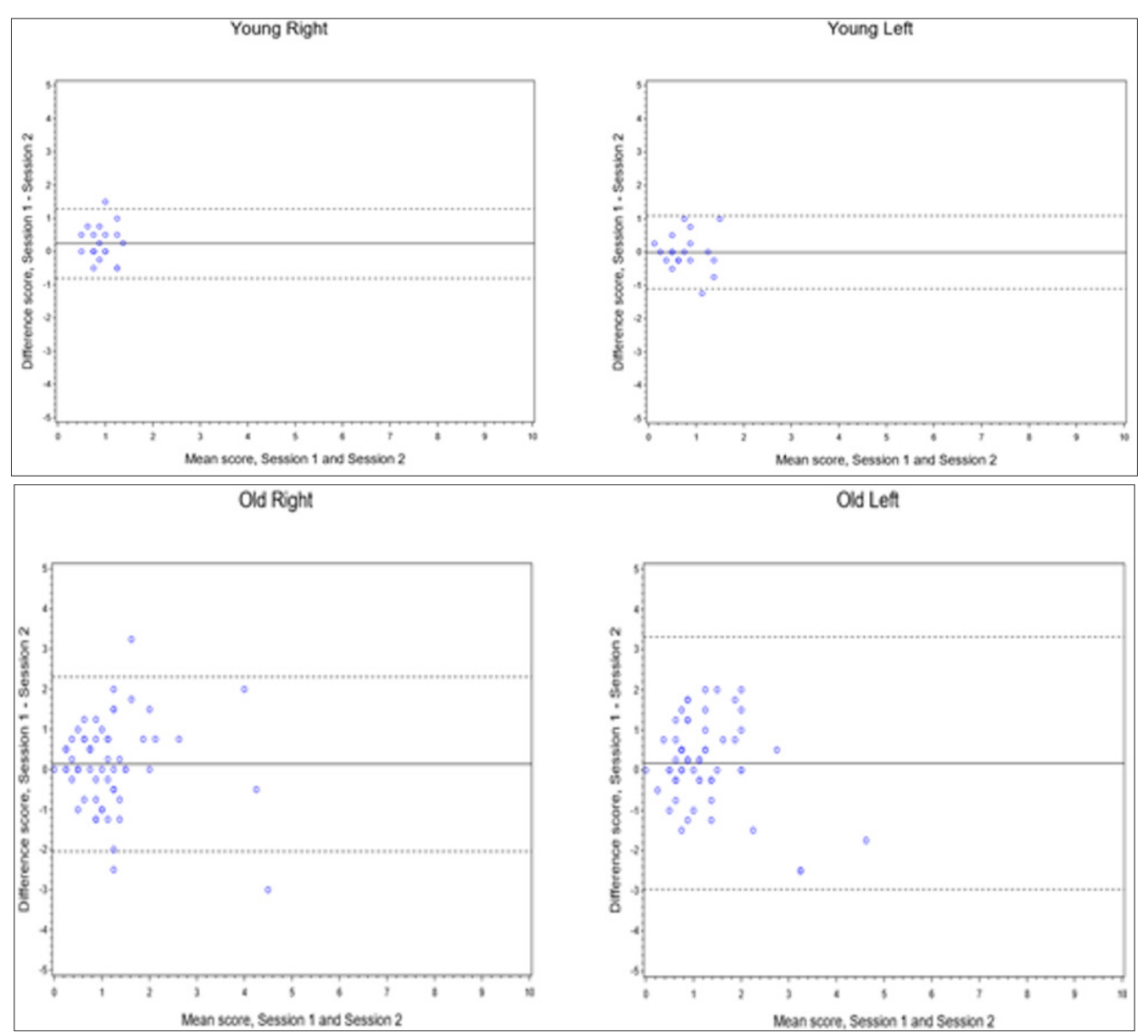

Figure 4: Bland-Altman plots for agreement between two testing sessions, position test, $22 \mathrm{~cm}$ distance (solid line, mean difference between testing sessions; dashed line, limits of agreement).

\section{Discussion}

The newly developed LEPT, a quantitative tool to assess proprioception performance of the lower extremity, was examined in this study. By reproducing distances of passive combined knee and ankle movements using a simple and cheap tool, a ratio scale assessment is obtained. It stands well with requirements of psychometric properties and does not require special equipment or training, is easily portable, and conforms to measures of clinical utility [10]. Overall, the study found differences in performance between old and young population, no difference between right and left lower extremities in older individuals, but a difference in young in the $22 \mathrm{~cm}$ distance. These findings justify the use of the Lower Extremity Position Test (LEPT) for testing the characteristic of intact or impaired proprioception of the lower extremity in older adults, through known groups validity [13]. Variability of outcomes was much wider in the older adult group, as shown in the BlandAltman analysis, and as suggested in earlier literature $[6,15]$.

A review by Goble et al. [6] reported that single joint proprioception matching tasks are performed with greater mismatch in elderly than in young participants in most studies, due to greater variability in individual performance. If an assessment tool is able to capture this variability in older adults, as opposed to homogeneity in young adults, it may suggest that this tool is sensitive to changes in proprioception with age in healthy older individuals. The ICC values indicated fair to good test-retest reliability for the assessment of the older subjects, suggesting the suitability of the tool for the assessment of these populations. In contrast, test-retest reliability for young, healthy individuals was poor. Similar poor test - retest reliability has been reported with unimpaired individuals in tests of thermal thresholds [16,17]. Since ICC depends on between subject variability, the ICC appears very low when the range of results is very narrow and is suggested not to be the relevant statistic for use [18]. In our group of young subjects, most distance reproductions were within one $\mathrm{cm}$ error at most. Thus, the range of error is very narrow, and the ICC appears very low, accordingly.

However, the narrow agreement range for this subject group observed, with the Bland-Altman plots, assures a minor difference in scores between tests when testing individuals with intact sensory function [19]. Differences in ICC results between left and right, for healthy young and older groups, and difference in t-test between right and left $22 \mathrm{~cm}$ distance in young, could be explained by prior findings of differences in position-matching ability between dominant and non-dominant upper extremities. Matching appears to be more accurate with the non-dominant upper extremity, and differences in acuity grow with cognitive demand [20]. With regard to the tool presented here, accuracy with increasing cognitive 
demand, or under different attention conditions, needs to be further investigated. This new assessment tool can be used for both screening and diagnosis purposes and for surveillance and treatment effectiveness outcome assessment, as replacement or add-on tool to existing non-quantitative clinical testing.

\section{Study Limitations}

a) This tool assesses combined movement of knee and ankle, and the exact motion of each within the general movement is not controlled;

b) Intertester reliability was not tested in this study;

c) While proprioceptive function of the lower extremity is primarily important during standing and walking, the test was conducted in the seated position. Therefore, its relevance to functional performance needs to be further validated [21]

d) Our choice of older population without sensory loss (exclusion of neuropathies and failure to detect the 5.07 monofilament might lead to a "healthier than general population" subject group.

\section{Suggestion for Further Research}

We suggest that additional studies be conducted to validate this tool with a wide population of older adults of different age groups (old versus very old), and in individuals with neurological diagnoses. Further we suggest assessing the need for both short $(12 \mathrm{~cm})$ and long $(22 \mathrm{~cm})$ distances. As clinical assessment of proprioception is usually performed by detecting passive movement and its direction, correlation of the proposed tool with the conventional method should be studied, and advantages of the new tool highlighted. Additional studies should evaluate correlations between this new assessment instrument and existing laboratory tools, such as post urography, etc. We would like to further investigate the variability of outcomes in elderly and correlations to fear of falls and actual falls.

\section{Conclusion}

The LEPT is a reliable and valid tool for the assessment of proprioception of the lower extremity in older adult population.

\section{References}

1. Hillier S, Immink M, Thewlis D (2015) Assessing Proprioception: A Systematic Review of Possibilities. Neurorehabil Neural Repair 29(10): 933-949.

2. Proske U, Gandevia SC (2012) The Proprioceptive Senses: Their Roles in Signaling Body Shape, Body Position and Movement, and Muscle Force. Physiological Reviews, 92(4) : 1651-1697.

3. Anacker S L, Di Fabio RP (1992) Influence of sensory inputs on standing balance in community- dwelling elders with a recent history of falling. Physical Therapy 72(8): 575-581.

4. Ko SU, Simonsick EM, Deshpande N, Studenski S, et al. (2016) Ankle Proprioception-Associated Gait Patterns in Older Adults: Results from the Baltimore Longitudinal Study of Aging. Med Sci Sports Exerc 48(11): 2190-2194.

5. Burns E R, Stevens JA, Lee R (2016) The direct costs of fatal and non-fatal falls among older adults - United States. J Safety Res 58: 99-103.

6. Goble DJ, Coxon JP, Wenderoth N, Van Impe A, Swinnen SP, et al. (2009) Proprioceptive sensibility in the elderly: Degeneration, functional consequences and plastic-adaptive processes. Neuroscience \& biobehavioral reviews, 33(3): 271-278.

7. Shaffer S W, Harrison AL (2007) Aging of the somatosensory system: a translational perspective. Physical Therapy, 87(2): 193-207.

8. Han J, Waddington, G Adams, R Anson J, Liu Y, et al. (2016) Assessing proprioception: A critical review of methods. Journal of Sport and Health Science, 5(1): 80-90.

9. Krewer C, Van de Winckel A, Elangovan N, Aman J E, Konczak J, et al. (2016) "Commentary on: Assessing proprioception: A critical review of methods" by Han et al. Journal of Sport and Health Science 5(1): 91-92.

10. Connell LA, Tyson SF (2012) Measures of sensation in neurological conditions: a systematic review. Clinical rehabilitation 26(1): 68-80.

11. Dunn W, Griffith J, Morrison MT, Tanquary J, Sabata D, et al. (2013) Somatosensation assessment using the NIH Toolbox. Neurology,80(11suppl 3): 41-44.

12. Terryberry K J (2012) Normative Values for Foot Sensation: Challenging the 5.07 Monofilament. The journal of diabetic foot complications 4(1): 16-25.

13. Portney L G, Watkins M P (2000) Foundations of clinical research: Applications to practice (2nd Eds ed.). Upper Saddle River, NJ, Prentice Hall, Inc: Prentice Hall, Inc.

14. Bland J M, Altman DG (1986) Statistical methods for assessing agreement between two methods of clinical measurement. Lancet 1(8476): 307310.

15. Kaplan FS, Nixon J E, Reitz M, Rindfleish L, Tucker J, et al. (1985) Agerelated changes in proprioception and sensation of joint position. Acta Orthopaedica Scandinavica 56(1): 72-74.

16. Moloney NA, Hall TM, O'Sullivan TC, Doody CM, et al. (2011) Reliability of thermal quantitative sensory testing of the hand in a cohort of young, healthy adults. Muscle \& nerve 44(4) : 547-552.

17. Ofek H, Alperin M, Knoll T, Livne D, Laufer Y, et al. (2018) Assessment of texture discrimination ability at the sole of the foot in subjects with chronic stroke compared with young and elderly subjects with no neurological deficits: a reliability and validity study. Disabil Rehabil 40(16): 1960-1966.

18. Weir JP (2005) Quantifying test-retest reliability using the intraclass correlation coefficient and the SEM. The Journal of Strength \& Conditioning Research 19(1): 231-240.

19. Giavarina D (2015) Understanding bland Altman analysis. Biochemia Medica 25(2): 141-151.

20. Goble D J (2010) Proprioceptive acuity assessment via joint position matching: from basic science to general practice. Phys Ther 90(8): 11761184.

21. Spooner DM, Pachana NA (2006) Ecological validity in neuropsychological assessment: a case for greater consideration in research with neurologically intact populations. Arch Clin Neuropsychol 21(4): 327-337. 


\section{ISSN: 2574-1241}

DOI: 10.26717/BJSTR.2019.12.002306

Hadas Ofek. Biomed J Sci \& Tech Res

(C) (P) This work is licensed under Creative BY Commons Attribution 4.0 License

Submission Link: https://biomedres.us/submit-manuscript.php

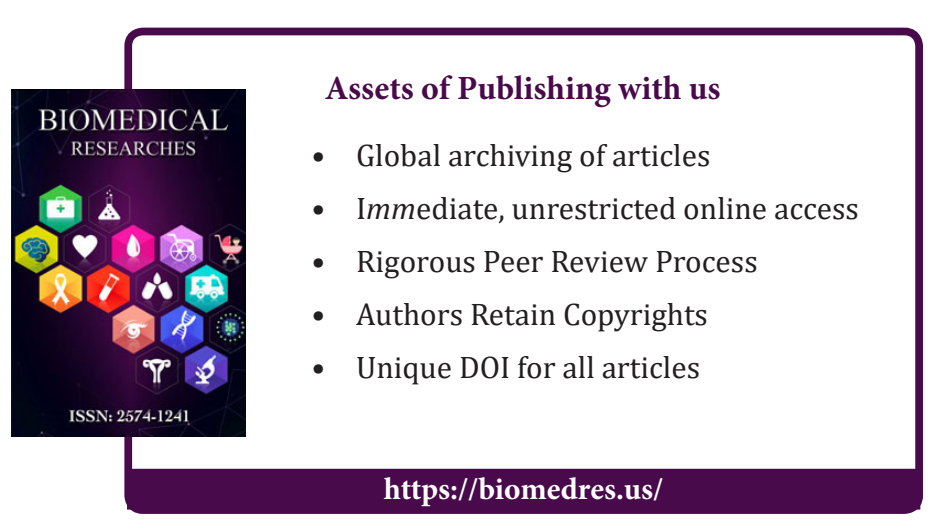

